clinicians. An extensive bibliography at the end of each chapter is also of value to those who may wish to pursue a particular aspect of the subject in greater depth. In addition the author's helpful comments in areas of dispute or deficient knowledge greatly add to the value of the book.

R. F. FISHER

Retrolentol Fibroplasia: A Modern Parable. By William A. Silverman. Pp. 246. \$23·50. Grune and Stratton: New York. 1980.

This book is one of a series of monographs in neonatology. and its author has played a major role in achieving an understanding of the nature of retrolental fibroplasia-the retinopathy came to light in Boston 1 year previously without any true understanding of its aetiology. Furthermore the author has woven into the text personal contributions from 26 people (such as Norman Ashton, Paul Chandler. Everett Kinsey, and Arnall Patz) who in different ways played vital roles in the unravelling of the mysteries of this devastating eye condition which seemed to emerge with unusual haste.

The book is regarded by the author as a 'modern parable' which he has felt compelled to write because of his belief 'that the unpleasant memory of the most dramatic epidemic of infantile blindness in recorded history was being repressed in the collective consciousness of medicine because it is too painful to recall.'

The association of the condition with prematurity was established by T. L. Terry in Boston in 1944, and before his death in 1946 he collected 117 cases. He also established the important fact that the condition in certain cases developed some time after birth, which was in conflict with the view which persisted until 1948 that it represented an inherent or acquired abnormality caused by factors which operated before birth or, at the latest. immediately thereafter. In 1948, however, William and Ella Owens at the Johns Hopkins Hospital observed in a certain number of premature infants the sequence of changes in the retinal blood vessels and in the retina as a whole during the development of retrolental fibroplasia beginning some weeks after birth.

It is natural that the emergence of a new condition of such devastating proportions from a visual point of view attracted the attention of many clinical and experimental observers, and within a relatively short time it became established that retrolental fibroplasia is induced initially by an oxvgen-rich atmosphere which causes a withering of the outgrowing peripheral retinal vessels in a state of prematurity. Subsequently there is a widely disorganised regrowth of these abnormal vessels on removal from the excessive oxvgen leading to the formation of grev-coloured masses which represent areas of detached retina. Finally a grev membrane develops which represents the totally detached retina covered by many enlarged blood vessels.

It might be expected that the rapid recognition of the true nature of retrolental fibroplasia would have led to a disappearance of the condition by a careful control of the administration of oxvgen to the premature child. but this has not been achieved to an accepted extent. However. this is natural because of the inevitable conflict between the paediatrician who has the task of maintaining life in the premature child and the ophthalmic surgeon who is aware of the risks of permanent blindness. This book discusses in detail the underlying problem. and it should be studied by all doctors who are concerned in the management of the premature infant.

KENNETH C. WYBAR

La Périphérie du fond d'Oeil. Eds. P. Bec, M. Ravault, J. L. Arné, C. Trepsat. Pp. 461. No price given. Masson: Paris. 1980.

This soft-back book is a review of the current state of knowledge about the retinal periphery and is a comprehensive review of that area. The first section deals with the anatomy, embryology, and physiological methods of examination and normal aspects of the retinal periphery. The book then goes on to describe pathological conditions in considerable detail.

My overall impression is that it certainly is of considerable use to the ophthalmologist in familiarising himself with many aspects of this important area of the eye. The book as a whole represents in the main a summary of our current state of knowledge and is profusely illustrated. Some of these illustrations are of somewhat inferior quality and are rather too small to be of much help. This particularly applies to the photographs. The book generously includes a large number of colour photographs, many of which are of excellent quality, but again some are not particularly satisfactory. There is an extensive bibliography from which the reader can easily refer to further work in the main subjects. The nature of the book means that there has been a certain amount of compression of information and this does at times give some apparent imbalance in the contents. However, in general it is to be recommended, though as it is in French many English speaking ophthalmologists will find it of rather limited use.

A. H. CHIGNELI.

\section{Handbook of Ophthalmology for Developing Coun-} tries. 2nd edn. By Geoffrey G. Bisley. Pp. 157. £4-50. Oxford University Press: Oxford. 1980.

The first edition of this handbook was reviewed by us in 1972. At that time we expressed the view that there was a need for a publication of this nature. and the fact that it has gone into a second edition only 8 years later shows that by and large it has fulfilled this need. The second edition is an improvement on the first, and most of the more recent developments in ophthalmology find a mention in its pages.

There is a useful section on rural ophthalmology contributed by $\mathrm{Dr} \mathrm{W}$. R. Burkitt and a valuable appendix on the local production of eye drops. The index is comprehensive and accurate. and one of the few minor criticisms that can be made is that the section on the ocular complications of leprosy could usefully be expanded.

The line drawings, particularly those in which red has been used to bring out a special feature are very helpful but the black-and-white plates, although probably excellent in the original. are something of a disappointment. Although written with an understandable emphasis towards East African ophthalmology, there is no doubt that this excellent and very reasonably priced handbook will command a wide audience in developing countries wherever they may be.

D. P. CHOYCF 